\title{
Pregnancy with Uterine Prolapse - Rare Cases with Distinct Labour Outcomes
}

\author{
Himanshi Agarwal ${ }^{1}$, Neema Acharya ${ }^{2}$, Deepti Shrivastava ${ }^{3}$, Shazia Mohammad ${ }^{4}$ \\ 1, 2,3,4 Department of Obstetrics and Gynaecology, Jawaharlal Nehru Medical College, Datta Meghe Institute of Medical \\ Sciences, Sawangi (M), Wardha (Deemed to Be University), Wardha, Maharashtra, India.
}

\section{INTRODUCTION}

Prolapse of uterus is a relatively uncommon condition during pregnancy. It is directly associated with maternal complications, spontaneous abortion, preterm labour and intra-uterine death. We report two cases; one patient came with prolapse of uterus in her present pregnancy while the other patient had history of prolapse in both, first and second pregnancy.

\section{PRESENTATION OF CASES}

\section{Case 1}

A 25-years-old pregnant, short stature with gravida 2, parity 1, living issue 1 with body mass index (BMI) $24.67 \mathrm{Kg} \mathrm{/} \mathrm{m}$, visited our hospital with twenty-nine weeks of pregnancy with a prolapsed uterus, having on and off pain in abdomen. On general examination patient was conscious, oriented and there were no associated high-risk factors. On per abdomen examination uterus corresponded to 26 weeks size with mild contractions present. Pelvic examination revealed pelvic organ prolapse, stage 3 , according to POP-Q classification. Uterine dissensus was of size of $20 \times 18 \mathrm{~cm}$, hyperaemic, and oedematous with minimal ulcerations as shown in the Figure 1 . The internal os of the cervical canal was closed, amniotic sac was not intact and irregular contractions were appreciated. Repeated ultrasonography revealed a normal foetus in the uterine cavity with isthmus of $0.6 \mathrm{~cm}$ and was partially protruding from the perineum of about $0.62 \times 0.64 \mathrm{~cm}$ with clear boundaries and cervical oedema was appreciated. Magnesium sulphate dressing was used to reduce oedema of prolapsed uterus. There was no history of bladder and bowel symptoms. The first baby was delivered by forceps delivery for maternal exhaustion as mentioned in her previous records and had no similar history of organ prolapse during previous pregnancy. In between two pregnancies there was no history of prolapse. Patient was farmer by occupation and had resumed her work 3 months after the delivery. In the present pregnancy associated with preterm labour, tocolytics (tab. nifedipine $10 \mathrm{mg}$ TDS) were started. The cervix was reposed inside the vagina with roller gauze packing and self-retaining foleys' catheter was put in. In-spite of all care patient progressed into active preterm labour and delivered spontaneously an extremely premature male baby, of 850 grams. After three days of postpartum period, the prolapsed uterus reduced to the size of $10 \times 10 \mathrm{~cm}$ below the level of umbilicus. By the end of seven days of postpartum period, the prolapsed uterus reduced further to the size of $7 \times 5$ $\mathrm{cm}$, and it was manually reposted back inside the pelvic cavity. She was given discharge on the eighth day of postpartum period. A telephonic postpartum followup on the 20th day conveyed that on standing or walking there was no lump prolapse. But due to increased abdominal pressure, such as while squatting and defecating, vaginal mass which was prolapsed could be palpated, with size of around $4 \mathrm{~cm} \times 3$ $\mathrm{cm}$. A vaginal pessary was advised to her of no. 5 as shown in the Figure 2 and proper follow up was taken for the same. She had no longer prolapse of uterus after 6 weeks of follow-up. Patient was advised and taught how to perform Kegel's exercise, to avoid lifting heavy weight, to prevent constipation, and controlled coughing.
Corresponding Author: Dr. Neema Acharya,

Professor,

Department of Obstetrics and

Gynaecology, Jawaharlal Nehru Medical College, Datta Meghe Institute of Medical Sciences, Sawangi (Meghe), Wardha, Maharashtra, India.

E-mail: neemasacharya@gmail.com

DOI: $10.14260 /$ jemds $/ 2021 / 74$

How to Cite This Article: Agarwal H, Acharya N, Shrivastava D, et al. Pregnancy with uterine prolapse - rare cases with distinct labour outcomes. J Evolution Med Dent Sci 2021;10(05):329332, DOI: 10.14260/jemds/2021/74

Submission 11-09-2020,

Peer Review 05-12-2020,

Acceptance 08-12-2020,

Published 01-02-2021.

Copyright (c) 2021 Himanshi Agarwal et al. This is an open access article distributed under Creative Commons Attribution License [Attribution 4.0 International (CC BY 4.0)] 


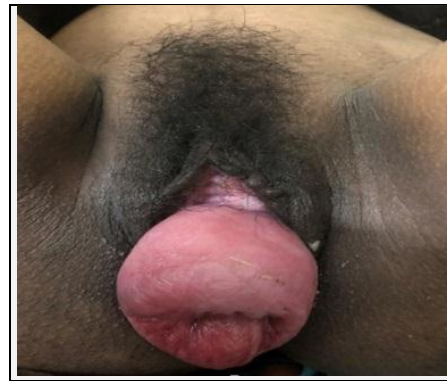

Figure 1. Pregnant Woman with Prolapsed Uterus of $20 \times$ $20 \mathrm{~cm}$ Size, Pink, Hyperaemic, and Oedematous with Minimal Ulcerations

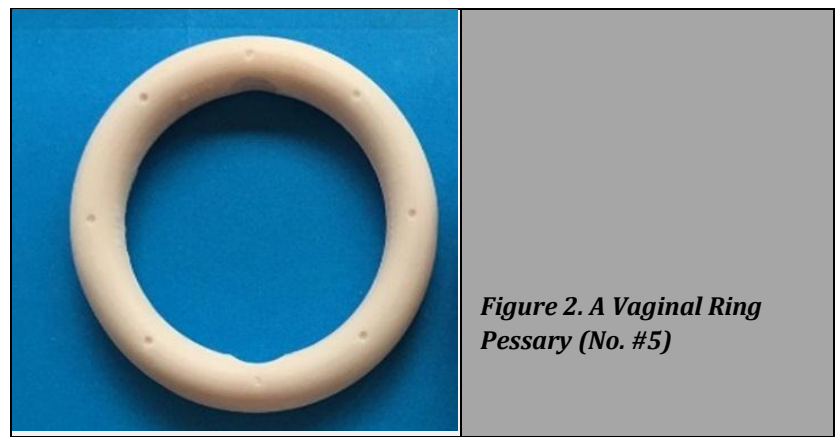

Case 2

A 21-years-old pregnant, gravida 2, parity 1, death 1 with body mass index (BMI) $23.92 \mathrm{Kg} / \mathrm{m}^{2}$, visited our hospital at $5^{\text {th }}$ month of gestation with a prolapsed uterus. As per the history, in her previous pregnancy she delivered a preterm, male baby who died after 15 days of birth due to pneumonia 1 year back. She came with similar complaint of prolapse of uterus in the previous pregnancy and was managed conservatively. In present pregnancy due to the fear of previous loss, she had a regular check-up in the antenatal period. During these visits, the patient was trained for insertion, removal and cleaning and storage method of ring pessary for the prolapse of uterus seen at 24 weeks of gestational age because of the weight of the baby. Patient complained for the same, but after 4 weeks she started having lower abdominal discomfort, after which she removed the pessary and started using aseptic perineal pad. Her cervix which was prolapsed could be repositioned back in pelvic cavity only on supine position. She continued her pregnancy with the mild prolapse of uterus without any aid. There was no increase in the prolapse on standing, walking or coughing. Later, at around $8^{\text {th }}$ month of pregnancy, she started complaining of pain in abdomen and was admitted in the hospital for the same. On general examination there was no bowel and bladder complaints with no association of any other high-risk factors. On per abdominal examination the uterus was 34 weeks size with cephalic presentation. On pelvic examination stage 1 pelvic organ prolapse by POP-Q classification was observed, with dry cervix as shown in Figure 3. She went into spontaneous active phase of labour and after the trial of labour, an emergency Caesarean section was carried out due to cervical dystocia and with the help of our experienced obstetricians and the team, a male child with 2100 grams was extracted out. The prolapsed portion of the uterus was reposted back, and the patient had normal introitus after childbirth. She was non-compliant for regular post-partum follow-up after childbirth.

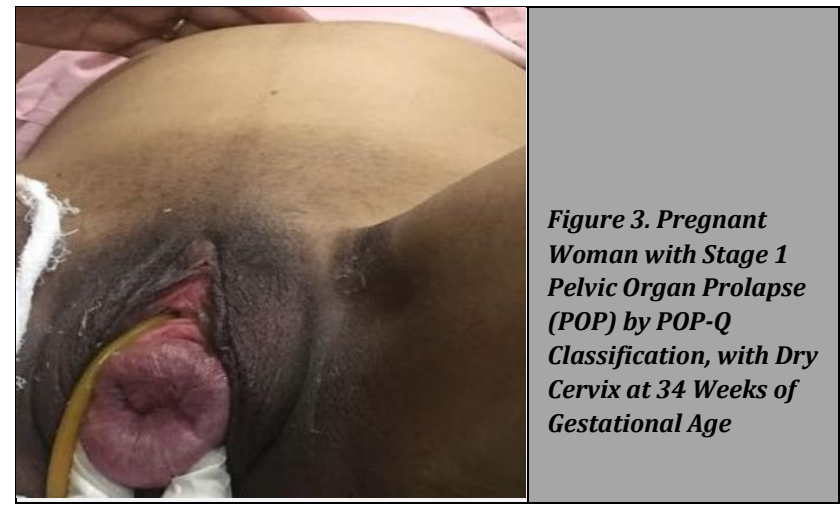

DISCUSSION

Due to change in demography, even fertile age women can have pelvic organ prolapse and if not treated timely, can hinder in pregnancy. Prolapse of uterus although rare is mostly seen in multiparous women. ${ }^{2}$ POP has been commonly visualised before and often gets resolved during pregnancy. Such patients have high chances of recurrence postdelivery. $5,6,7$ Acute onset of POP in pregnancy is more commonly seen; it usually comes in notice in the third trimester ${ }^{5}$ and it disappears after the patient gets delivered ${ }^{2}$ Chances of genital prolapse increases during pregnancy due to rise in physiological levels of cortisol and progesterone, due to which there is simultaneous softening and stretching of tissues of pelvic floor. Due to impaired blood flow and oedema of cervix leading to subsequent tissue anoxia, may become a contributing factor leading to an increase in the incidence of abortion and preterm labour with POP. ${ }^{8}$ Risk factors for prolapse of uterus can be congenital or acquired. Congenital factors comprise of congenital weakness in the tissues of pelvic floor by collagen defects (e.g. Marfan's syndrome, Ehlers-Danlos syndrome), abnormal structure of pelvis, mass related to uterus or ovary, thereby causing increased intraabdominal pressure. Acquired or obstetrical factors include multiparous woman, instrumental delivery, previous prolonged second stage of labour, first delivery at young age. Also, history of trauma to pelvis, any family history of prolapse of uterus and obesity are considered to be common risk factors for prolapse of uterus ${ }^{3,5}$

However, as discussed in the case above, there were no risk factors that are commonly associated with prolapse during pregnancy.9,10 POP can further lead to severe complications related to ante-peri and postnatal period. Severe antenatal issues include e.g. preterm labour, premature labour or miscarriage. ${ }^{11}$ Maternal mortality has also been reported with prolapse during pregnancy. ${ }^{12}$ The most important factor that causes inadequate cervical dilatation is cervical dystocia. Along with this, obstructed labour, cervical trauma and uterine rupture are reported.13

The Pelvic Organ Prolapse-Quantitation system classification, is an international multidisciplinary evaluation system established by the International Continence Society, ${ }^{14}$ which provides information about the anatomical / topographical position of all pelvic organs, including the descent, and the degree of vaginal sites, the uterus and bladder, as well as the small intestine (i.e. enterocele), and it 
provides information regarding perineal descent ${ }^{15}$ and alterations in the axis of the levator plate (Table 1).

\begin{tabular}{|c|c|}
\hline $\begin{array}{c}\text { Staging } \\
\text { I }\end{array}$ & $\begin{array}{c}\text { No Prolapse } \\
\text { II }\end{array}$ \\
The most distal portion of the prolapse is $>1 \mathrm{~cm}$ above the level of hymen \\
III & $\begin{array}{r}\text { The most distal portion of the prolapse is }>1 \mathrm{~cm} \text { below the hymen but } \\
\text { protrudes no further than } 2 \mathrm{~cm} \text { less than the total vaginal length } \\
\text { the prone is }<=1 \mathrm{~cm} \text { proximal to or distal to }\end{array}$ \\
IV & $\begin{array}{c}\text { Complete eversion of the total length of the vagina. The distal portion } \\
\text { protrudes at least the total vaginal length minus } 2 \mathrm{~cm} \text { beyond the hymen }\end{array}$ \\
Table 1.ICS (International Continence Society-2002) \\
POP-Q and Staging System.
\end{tabular}

Ring pessary is advised and recommended until the onset of labour. ${ }^{6,7}$ Vaginal ring pessary is usually inserted to support and protect the uterine structures in the pelvis and therefore to support prolapsed cervix after manual reposition as described in the $2^{\text {nd }}$ case of prolapse of uterus in multiparous woman during third trimester. Klawans and Kanter ${ }^{16}$ in 1949, advised to continue whole period of gestation with insertion of the Smith-Hodge pessary in patients with prolapse during pregnancy by restoring the cervix to its normal position above the hymen and supporting it in between the pubic symphysis and coccyx, which has similar action to paracervical support. ${ }^{17}$ Complications associated with pessaries like vaginal mucosal erosion, discharge, odour and vaginal abrasions and urinary complications should be kept in mind while using it.18

A variety of complications were reported in different studies. Gaikwad et al conducted a study on nitrosative stress in pregnancy induced hypertension. ${ }^{19}$ Singh et al conducted a study on colour Doppler evaluation in high-risk pregnancy and perinatal outcomes. ${ }^{20}$ Bhatia et al reported a rare case of postpartum haemolytic uremic syndrome (PHUS) with posterior reversible encephalopathy syndrome (PRES) complicating pregnancy. ${ }^{21}$ Inamdar et al studied about coexistence of hypertriglyceridemia and hypercholesterolemia with gestational diabetes mellitus in pregnancy. ${ }^{22}$ Kumari et al reported about comparison of transvaginal colour Doppler ultrasound and progesterone level estimation in outcome of threatened abortion in early pregnancy. ${ }^{23}$ Salampuria et al reported on acute respiratory distress syndrome during pregnancy and post-partum. ${ }^{24}$ Ladke et al reported on parasitic fibroid as complication of post-laparoscopic morcellation. ${ }^{25}$ Few other studies on complications of pregnancies have been reported by Agrawal et al, ${ }^{26}$ Kolli et al ${ }^{27}$ and Khan et al. ${ }^{28}$

There was no evidence of similar complication in our patient. Even after using different types of vaginal pessaries, the success rate with this management is recorded less in literature since pessaries tend to fell off after few days. The type and size of ring pessary for this patient in case 2, fitted perfectly and was managed successfully for few weeks, contrary to the literature. The patient was demonstrated as to how the pessary should be used. Thus, while selecting the type of pessary for patient, the shape and its size and the patient's congruity to the treatment should be kept in mind for successful management for the prolapse of uterus.

\section{CONCLUSIONS}

Every obstetrician and gynaecologist should be aware of antenatal and intrapartum management of pregnancy complicated with prolapse and the need for close monitoring and active intervention at times. The progress of labour should be monitored carefully to rule out cervical dystocia, in which case Caesarean section should be the mode of delivery to avoid risk of cervical tears and post-partum haemorrhage.

Further management of prolapse uterus should be decided after re-evaluation of the case as the prolapse may get corrected after involution of uterus after 6 weeks. Those cases in which prolapse persists should be counselled for corrective treatment.

Prolapse during pregnancy suggests that patients may have pelvic floor dysfunction and may be susceptible for prolapse uterus in later life. Hence, even in those patients in whom uterus returns to normal position, they should be trained for pelvic floor muscle strengthening exercises and to be kept under regular gynaecological surveillance of pelvic floor rehabilitation services to prevent future recurrence of prolapse.

\section{List of Abbreviations}

IUD: Intra-Uterine Death; BMI: Body Mass Index; POP: Pelvic Organ Prolapse, POP-Q: Pelvic Organ Prolapse Quantification

Financial or other competing interests: None.

Disclosure forms provided by the authors are available with the full text of this article at jemds.com.

\section{REFERENCES}

[1] Patel PD, Amrute KV, Badlani GH. Pelvic organ prolapse and stress urinary incontinence: a review of etiological factors. Indian J Urol 2007;23(2):135-41.

[2] Guariglia L, Carducci B, Botta A, et al. Uterine prolapse in pregnancy. Gynecologic and Obstetric Investigation 2005;60(4):192-4.

[3] Tsikouras P, Dafopoulos A, Vrachnis N, et al. Uterine prolapse in pregnancy: risk factors, complications and management. The Journal of Maternal Fetal \& Neonatal Medicine 2014;27(3):297-302.

[4] De Vita D, Giordano S. Two successful natural pregnancies in a patient with severe uterine prolapse: a case report. Journal of Medical Case Reports 2011;5(1):459.

[5] Horowitz ER, Yogev Y, Hod M, et al. Prolapse and elongation of the cervix during pregnancy. International Journal of Gynecology \& Obstetrics 2002;77(2):147-8.

[6] Hill PS. Uterine prolapse complicating pregnancy. A case report. The Journal of Reproductive Medicine 1984;29(8):631-3.

[7] Brown HL. Cervical prolapse complicating pregnancy. Journal of the National Medical Association 1997;89(5):346-8.

[8] Nóbrega LM, Nobrega MM, da Silva VI, et al. Uterine prolapse during pregnancy: a case report. Indian J Case Reports 2018.

[9] Karataylı R, Gezginç K, Kantarcı AH, et al. Successful treatment of uterine prolapse by abdominal hysteropexy performed during cesarean section. Archives of Gynecology and Obstetrics 2013;287(2):319-22. 
[10] Kart C, Aran T, Guven S. Stage IV C prolapse in pregnancy. International Journal of Gynecology \& Obstetrics 2011;112(2):142-3.

[11] Biaggi A, Conroy S, Pawlby S, et al. Identifying the women at risk of antenatal anxiety and depression: a systematic review. J Affect Disord 2016;191:62-77.

[12] Partsinevelos GA, Mesogitis S, Papantoniou N, et al. Uterine prolapse in pregnancy: a rare condition an obstetrician should be familiar with. Fetal Diagnosis and Therapy 2008;24(3):296-8.

[13] Mohamed-Suphan N, Ng RKW. Uterine prolapse complicating pregnancy and labor: a case report and literature review. International Urogynecology Journal 2012;23(5):647-50.

[14] Auwad W, Freeman RM, Swift S. Is the pelvic organ prolapse quantification system (POPQ) being used? A survey of members of the International Continence Society (ICS) and the American Urogynecologic Society (AUGS). International Urogynecology Journal Pelvic Floor Dysfunct 2004;15(5):324-7.

[15] Bump RC, Mattiasson A, Bø K, et al. The standardization of terminology of female pelvic organ prolapse and pelvic floor dysfunction. American Journal of Obstetrics and Gynecology 1996;175(1):10-7.

[16] Klawans AH, Kanter AE. Prolapse of the uterus and pregnancy. American Journal of Obstetrics \& Gynecology 1949;57(5):939-46.

[17] Tabaquero MA. Pelvic organ prolapse in pregnancy. Obstet Gynecol Int J 2017;8(2):00284.

[18] Sulak PJ. Nonsurgical correction of defects, the use of vaginal support devices. Te Linde's Operative Gynecology. $8^{\text {th }}$ edn. Philadelphia, Pa: Lippincott-Raven 1997;8:10823.

[19] Gaikwad KB, Joshi NG, Selkar SP. Study of nitrosative stress in 'pregnancy induced hypertension'. Journal of Clinical and Diagnostic Research 2017;11(3):BC06-8.

[20] Singh H, Agrawal A, Bhake A, et al. Colour Doppler evaluation in high - risk pregnancy and perinatal outcome. Journal of Evolution of Medical and Dental Sciences 2018;7(43):4603-8.

[21] Bhatia A, Bhagwat A, Acharya S, et al. Postpartum haemolytic uremic syndrome (PHUS) with posterior reversible encephalopathy syndrome (PRES) complicating pregnancy: a rare case report. Journal of Clinical and Diagnostic Research 2019;13(4):OD1-3.

[22] Inamdar SA, Agarwal H, Acharya S, et al. Coexistence of hypertriglyceredemia and hypercholesterolemia with gestational diabetes mellitus in pregnancy: a case report. Medical Science 2020;24(102):594-8.

[23] Kumari P, Wanjari S. Comparison of transvaginal colour Doppler ultrasound and progesterone level estimation in outcome of threatened abortion in early pregnancy. Journal of Clinical and Diagnostic Research 2020;14(4):QC11-5.

[24] Salampuria S, Jajoo S, Acharya S. Acute respiratory distress syndrome during pregnancy and post - partum a case series with spectrum of near miss to mortality. Journal of Evolution of Medical and Dental Sciences 2019;8(49):3724-6.

[25] Ladke AB, Palaskar PA, Bhivsane VR. Parasitic fibroid: complication of post - laparoscopic morcellation. Journal of Obstetrics and Gynecology of India 2020.

[26] Himanshi A, Inamdar A, Inamdar SA, et al. Posterior reversible encephalopathy syndrome in a patient with eclampsia. Journal of Evolution of Medical and Dental Sciences 2019;8(48):3643-45.

[27] Kolli SN, Agrawal M, Khithani Y, et al. Correlation of thyroid disorders with abnormal uterine bleeding (AUB). Journal of Evolution of Medical And Dental Sciences 2020;9(7):398-401.

[28] Khan A, Acharya N, Koshatwar M, et al. Uterine artery embolization: a boon for a near miss case of pseudoaneurysm. Journal of Clinical and Diagnostic Research 2020;14(1):QD1-3. 